094

\title{
INFEZIONE DA PAPILLOMAVIRUS: STUDIO DI PREVALENZA DEI GENOTIPI AD ALTO E BASSO RISCHIO ONCOGENICO
}

\author{
Camporiondo M.P., Gallone D., Luzietti V., Natili S., \\ Tronci M. \\ Laboratorio Di Microbiologia e Virologia, \\ Azienda Ospedaliera San Camillo-Forlanini, \\ Piazzale Carlo Forlanini I, 00152 Roma
}

\section{Introduzione}

Sono noti circa 100 tipi diPapillomavirus (HPV), circa 1/5 è associato a patologie del tratto genitale.

Nella popolazione sessualmente attiva la localizzazione più frequente è a livello della cervice uterina. HPV è rilevabile con significativa frequenza nelle lesioni di basso grado (LSIL), con frequenza maggiore in quelle di alto grado (HSIL) mentre è fortemente associato (99.7\%) al tumore della cervice. La diversa capacità oncogenica degli HPV consente di suddividerli in genotipi ad alto rischio (AR) e basso rischio(BR).

Tra settembre 2002-maggio 2005 abbiamo ricercato il DNA di HPV su 960 prelievi cervicali di donne provenienti dall'ambulatorio ginecologico dell'ospedale San Camillo di Roma. L'età media è stata di 34.2 anni. Lo scopo dell' indagine è stato quello di valutare la prevalenza dei diversi genotipi HPV.

\section{Metodi}

L'iter diagnostico dei campioni è iniziato con una PCR screening per HPV-DNA con i primer MY09-MY11 (regione L1). I campioni positivi sono stati tipizzati utilizzando la tecnica INNOLIPA che individua 25 genotipi di cui 14 AR $(16,18,31,33,35,39,45,51,52,58,59,66,68)$ e 11 BR $(6,11,40,42,43,44,53,54,56,70,74)$.

\section{Risultati}

160 campioni $(17.6 \%)$ sono risultati positivi allo screening per HPV-DNA.

Di questi 120 sono stati tipizzati con l'INNOLIPA. I genotipi AR più frequenti sono stati: $16(25.0 \%), 52(16.0 \%), 18$ e $31(11.7 \%), 66(10.8 \%) 51(10.0 \%), 56$ (7.7\%), 58 (6.7\%), gli altri con valori inferiori al $5 \%$.

I genotipi BR più frequenti sono stati: 11 (26.7\%), 53 $(24.2 \%), 6(19.2 \%)$, gli altri con valori inferiori al $5 \%$.

Inoltre $41 / 120$ campioni (34.2\%) avevano uno o più genotipi $\mathrm{AR}, 48 / 120$ (40.0\%) uno o più genotipi $\mathrm{BR}, 31 / 120$ (25.8\%) li avevano entrambi, 4/120 (3.2\%) erano negativi.

\section{Conclusioni}

Dai risultati emerge nei genotipi AR il 16 come quello maggiormente rappresentato, seguito dal 52 che prevale rispetto al 18 e al 31; tra i genotipi BR dopo l'11, prevale il 53 rispetto al 6 . 